\title{
Oral health conditions and activities of daily living in an elderly population in Brazil
}

\section{Abstract}

Objective: To analyze the relationship between the oral health status and functional capacity in performing basic activities of daily living of a population of elderly persons. Method: A cross-sectional population-based study with 441 individuals aged 60 years or over both genders was performed in the municipality of Macaíba, Rio Grande do Norte. From intraoral epidemiological examination, the degree of caries attacks (CPO-D index), periodontal condition (CPI and PIP indexes), the use and need for dental prosthesis and the presence of oral lesions were evaluated. Independence in Activities of Daily Living was used to evaluate functional capacity. Socioeconomic and demographic characteristics were surveyed using a structured questionnaire. Results: Oral health variables were subjected to factor analysis, which resulted in four indicators. There was no association between these indicators and the functional capacity of the elderly. Gender, age, presence of caregiver, dominant area of residence, time of last visit to the dentist, type of care sought during such visit and self-perception regarding prosthesis replacement were significantly associated with oral health indicators. Conclusion: Given the non-identification of the effect of functional capacity on the oral health of the elderly, the time of measurement of the events investigated should be considered. It is suggested that dependency among the elderly occurs at different times from when the consequences of oral problems are observed, considering the cumulative effects of a previous history of invasive dental care.

Keywords: Oral Health. Elderly. Disabled Persons.

\footnotetext{
Secretaria de Saúde Pública do Estado do Rio Grande do Norte. Natal, Rio Grande do Norte, Brasil.

2 Universidade Federal do Rio Grande do Norte, Programa de Pós-graduação em Saúde Coletiva. Natal, Rio Grande do Norte, Brasil.

3 Universidade Federal do Rio Grande do Norte, Departamento de Odontologia. Natal, Rio Grande do Norte, Brasil.
}

Correspondência/Correspondence

Diviane Alves da Silva

E-mail: vianealves@yahoo.com.br
Diviane Alves da Silva'

Yan Nogueira Leite de Freitas ${ }^{2}$ Tamires Carneiro de Oliveira²

Romerito Lins da Silva ${ }^{3}$ Carla Patrícia de Castro Pegado ${ }^{3}$

Kenio Costa de Lima² 


\section{INTRODUCTION}

Population aging is one of the greatest challenges facing contemporary public health. Functional incapacity, characterized by restrictions in the performance of normal activities ${ }^{1}$, is one of the most serious problems resulting from this chronological process. The oral health of elderly persons, in turn, is widely recognized as precarious due to the cumulative effects of oral diseases, in addition to the prevalence of an invasive model of dental care. This area merits further research, in particular through populationbased epidemiological studies, as tooth loss, the main issue affecting the oral health of elderly persons, often results in the development of significant incapacities that are not always perceived as relevant functional problems ${ }^{2,3}$.

Analysis of the dimensions of the functional capacity and oral health of elderly persons, with the aim of identifying the possible effects of different levels of dependence on the oral health status of these individuals and facilitating the diagnosis of these populations with a view to strategic planning based on specific public policies, is also important in order to identify associations, the consequences of which can be detrimental to the state of general health and to the quality of life of individuals ${ }^{4-7}$.

Few Brazilians studies have been dedicated to the investigation of such associations. In addition, none of the relevant studies employ a methodology that confers population representativeness. One study carried out in the city of São Paulo aimed to estimate the prevalence of oral problems among elderly persons, identifying that frailer individuals were more in need of dental prostheses ${ }^{8}$. Another example was a study carried out with elderly persons living in small geriatric care facilities in Porto Alegre, in the state of Rio Grande do Sul, which identified a lower average number of teeth with biofilm among independent individuals than among those who were moderately or totally dependent?

The present study proposed to analyze the relationship between the oral health status of an elderly population and the level of dependence of these individuals, based on their ability to perform basic activities of daily living. The study aimed to evaluate the hypothesis that loss of functional capacity in the performance of basic activities of daily living is associated with an inferior oral health profile among elderly persons.

\section{METHOD}

Population, sample and ethical conditions

A cross-sectional study was carried out with a representative sample of the elderly population of Macaíba, a municipality located in the north east of Brazil, $21 \mathrm{~km}$ from Natal, in the state of Rio Grande do Norte. The total population of this municipality in 2010 was 69,467 inhabitants, of whom 6,620 were aged 60 years or over ${ }^{10}$.

The calculation of the sample size of the study was based on the prevalence of edentulism among elderly persons in Brazil, according to a national survey on oral health carried out in $2003(60.8 \%)^{11}$, as well as the size of the elderly population of the municipality in 2000. Edentulism was chosen as a prevalence parameter as it represents the most common oral health problem among elderly persons. A 10\% error margin, 95\% confidence level, design effect of 1.5 and 20\% non-response rate were applied. Calculation of the sample was concluded with finite population correction, resulting in an estimated sample of 428 individuals. However, 466 individuals were identified as eligible for the study, of which 441 were elderly. This discrepancy was due to the use of the year 2000 in the sample calculation as a reference for the size of the elderly population of the municipality, in addition to census sector data from the year 2007. Individuals of both genders aged 60 years or over were eligible to participate in the study.

The protocol of the study was approved by the Research Ethics Committee of the Universidade Federal do Rio Grande do Norte (the Federal University of Rio Grande do Norte) under expert opinion no. 340/2009-CEP/UFRN. Prior to data collection, participants, along with their caregivers, received instructions for the survey and signed a Free and Informed Consent Form (FICT).

\section{Sampling Procedures}

A probabilistic base is a fundamental condition for the representativeness of a sample study ${ }^{12}$. For the enrollment of individuals in the present study, 
the technique of probabilistic cluster sampling was applied, with two stages of random draws, the first corresponding to the census sectors and the second to households.

For the first draw, it was determined that there would be 30 sectors, as this was considered an ideal number of points from which a good dispersion of data can be achieved ${ }^{13}$. In addition, two other supplementary sectors were drawn in case of any operational impediment.

The second stage of the draw corresponded to households and was carried out in loco at the time of data collection. For this purpose, a fraction of the sample corresponding to the range of households to be visited by the researchers was calculated. This calculation resulted in a fraction approximately equal to 7 .

\section{Data collections}

Data was collected between March 2010 and March 2011, by means of interviews and intraoral epidemiological examinations. Individuals who participated in the study were those who were at home at the time of data collection, or on one of up to three subsequent visits by the researcher.

The clinical record form was based on the model used in the most recent survey of the oral health status of the Brazilian population ${ }^{12}$. In the oral exams, previously sterilized oral mirrors and periodontal probes recommended by the World Health Organization (WHO) were used. In these examinations, the caries attack rate was evaluated using the DMFT index (number of decayed, missing and filled permanent teeth) while periodontal condition was assessed using the community periodontal index (CPI) and periodontal attachment loss index (PALI). The use and need for dental prosthesis and the presence of soft tissue alterations were also verified.

Interviews were carried out and a questionnaire applied concerning socioeconomic and demographic variables related to general health, self-care and access to oral health services. The evaluation of functional capacity was based on the Katz Index of Independence in Activities of Daily Living (Katz Scale), which classifies an individual as independent or dependent in the performance of six functions: feeding, bathing, dressing, transferring, toileting and continence ${ }^{14}$.

In order to ensure the reliability and reproducibility of the data, the four examiners participating in the study were trained and calibrated. This procedure consisted of discussions regarding the data collection instruments and addressed theoretical aspects regarding the variables, codes and criteria of the indices used in oral exams. In addition, the examiners were calibrated for the oral examinations. The Kappa coefficient values of between 0.61 to 1.00 obtained were considered acceptable in literature, and therefore indicative of the good reproducibility of the data ${ }^{12}$.

Statistical analysis

A descriptive analysis of the variables was carried out to characterize the sample, according to the dimensions investigated and oral health status. The oral health variables were submitted to factor analysis, identifying common factors, in order to synthesize the relations observed between them ${ }^{15}$. These factors, in turn, were dichotomized by the median value of the factorial loads.

Some independent variables were dichotomized by median values (age, education, medication expenditure, diseases reported, family income and household density) while data distribution was considered for dichotomization of the variables with more than two categories. Finally, the functional capacity variable, originally consisting of eight categories, was dichotomized between individuals totally independent in the performance of activities of daily living and those dependent in the performance at least one of the activities.

Associations between the dependent and independent variables were verified using the chisquared and Fisher's exact tests, with a significance level of $5 \%$. Simultaneous logistic regression was used to identify the associations of the independent variables with the study outcome. In the final 
model, all the variables with a $\mathrm{p}$ value below 0.2 in the bivariate associations were included. It should be noted that the sample was considered to be complex in nature due to use of the probabilistic sampling method (by clusters), which is recognized as a complex sampling design ${ }^{16}$. Finally, in order to test the consistency of the results obtained from the statistical analysis carried out prior to the sample treatment, as well as the population representativeness of these results, new descriptive and bivariate analyzes were carried out for the set of variables used in the study.

\section{RESULTS}

A total of 441 elderly persons were registered for participation out of 466 individuals eligible for the study. Some characteristics from the investigated sample are presented in Table 1. None of the individuals had more than two full years of study, while for marital status, individuals with stable partners, whether married or unmarried, predominated, (57.4\%). The percentage of widowed individuals (32.4\%) was also noteworthy. There was also a greater prevalence of individuals who shared their household with a spouse plus other relatives $(42.6 \%)$, or only other relatives $(35.1 \%)$. These individuals generally remained in the company of the elderly individuals, occupying the role of family caregiver or financial provider (Table 1).

A caregiver was considered present in cases where an individual characterized as caregiver and/ or responsible person and/or daily care provider for the elderly person was present, whether or not this individual was paid. For this variable, elderly persons who did not have caregivers or who did not report the need for daily care predominated $(86.4 \%)$. Regarding the area of residence of the elderly individuals, the great majority reported residing in urban areas in the countryside of the state for most of their lives $(51.7 \%)$. 
Table 1. Sociodemographic characteristics, health status and oral health of study participants ( $\mathrm{n}=441)$. Natal, Rio Grande do Norte, 2011.

\begin{tabular}{|c|c|}
\hline Sociodemographic characteristics & Mean (sd) \\
\hline Age & $71.7( \pm 8.76)$ \\
\hline Education & $2.17( \pm 2.74)$ \\
\hline Family income (minimum salaries) & $2.00( \pm 1.19)$ \\
\hline Household crowding & $0.65( \pm 0.37)$ \\
\hline Socioeconomic and demographic characteristics & $(\%)$ \\
\hline Female & 68.3 \\
\hline Single & 4.8 \\
\hline Married & 57.4 \\
\hline Widowed & 32.4 \\
\hline Separated & 5.4 \\
\hline Live alone & 6.6 \\
\hline Live with spouse & 15.6 \\
\hline Live with spouse and other relatives & 42.6 \\
\hline Live with other relatives & 35.1 \\
\hline Receive retirement pension & 77.1 \\
\hline Live in own house & 83.4 \\
\hline Health status & Average (sd) \\
\hline Self-reported illnesses & $1.5( \pm 1.2)$ \\
\hline Health status & $(\%)$ \\
\hline Dependency in at least one ADL & 10.4 \\
\hline Regular use of medication & 72.8 \\
\hline Recent fall & 11.8 \\
\hline Bone fracture post 60 years of age & 9.5 \\
\hline Current smoker & 21.3 \\
\hline Former smoker & 49.3 \\
\hline Current alcohol dependency & 7.0 \\
\hline Former alcohol dependency & 24.4 \\
\hline Oral health variables & Average (sd) \\
\hline Average DMFT & $28.1( \pm 5.77)$ \\
\hline Oral health variables & $(\%)$ \\
\hline Edentulism & 50.8 \\
\hline Positive self-perceived need for prosthesis replacement & 26.5 \\
\hline Use of public dental service for last visit & 63.9 \\
\hline Coverage through the Family Health Strategy & 82.5 \\
\hline
\end{tabular}

sd: standard deviation of mean; ADL: Activities of daily living; DMFT: Number of decayed, missing and filled teeth. 
Regarding the socioeconomic condition variables, most individuals received a retirement pension, with the majority receiving the minimum amount (U\$315.02), which to a certain extent accounts for the low average family income of twice the minimum salary (U\$630.05) since, in most cases, the elderly person was the only provider of support for the family. Most of the individuals resided in their own home (83.4\%) and were not included in government aid programs (90.0\%). Among those who did receive such aid, the most common program was Bolsa Família (Family Welfare) (70.5\%). As regards household crowding, measured by the number of people per room, there was an average of slightly more than 0.6 people/room in the households of the individuals interviewed.

Finally, the most reported form of medication acquisition was the receipt of free products at health units or centers in the municipality. The general health status of the individuals was analyzed using certain variables related to systemic conditions, as well as habits of smoking and alcohol dependency. The average number of diseases for which each individual took daily medication was $1.2( \pm 1.1)$ on average. The regular consumption of medicines among the studied population was notable, with the majority of individuals reporting regular use. Antihypertensive (57.2\%) and antidiabetic (16,3\%) were the most common forms of medication.

It was observed that, in the majority of cases, individuals had not suffered a fall in the four weeks prior to the time of the investigation, nor had they suffered a bone fracture after the age of 60 . The majority of individuals were also found not to have current or previous habits of smoking or alcohol dependency. However, the high percentage of the elderly individuals who had formerly used tobacco is worth noting. Regarding functional capacity, among the individuals who were dependent in at least one function, the most prevalent were those who needed assistance in the performance of five functions $(30.4 \%)$, or in other words, individuals close to becoming dependent in all activities of daily living.

Regarding oral health characteristics, the last visit of individuals to the dentist was over two years before in the majority of cases (62.4\%), with the public dental service being most utilized (63.9\%). The average DMFT value of the investigated sample revealed that the majority of individuals had missing teeth $(94.3 \%)$. Total loss of teeth was observed in more than half of the studied sample and functional edentulism (absence of up to 20 teeth - functional dentition) was encountered in $92.7 \%$ of individuals. Root caries, a common condition among the elderly population, were present in $28.1 \%$ of the study participants.

The periodontal condition of the elderly persons was evaluated by the observation of gingival bleeding, dental calculus and periodontal pockets, which were present in $66.3 \%, 77.9 \%$ and $19.3 \%$ of the individuals studied, respectively. Regarding the use and need for a prosthesis, it was observed that $46.7 \%$ of the individuals used an upper prosthesis, whereas only $27.8 \%$ used a lower prosthesis. The need for such prostheses was, however, observed in $80 \%$ of the individuals for the upper arch and in $86.4 \%$ for the lower arch.

Prior to the tests of association, factor analysis was employed to reduce the number of dependent variables used in the study. Using the principal components analysis method, four representative factors were chosen to represent the oral health status of the studied population. One of the justifications for using this number was the fact that together the chosen factors accounted for $77.41 \%$ of total variance for the variables included in the analysis model. The dependent variables of this study were therefore composed of these four factors. Figure 1 presents the results of factor analysis with the percentage of variance displayed for each factor, as well as for each set of variables, grouped according to their correlations. 


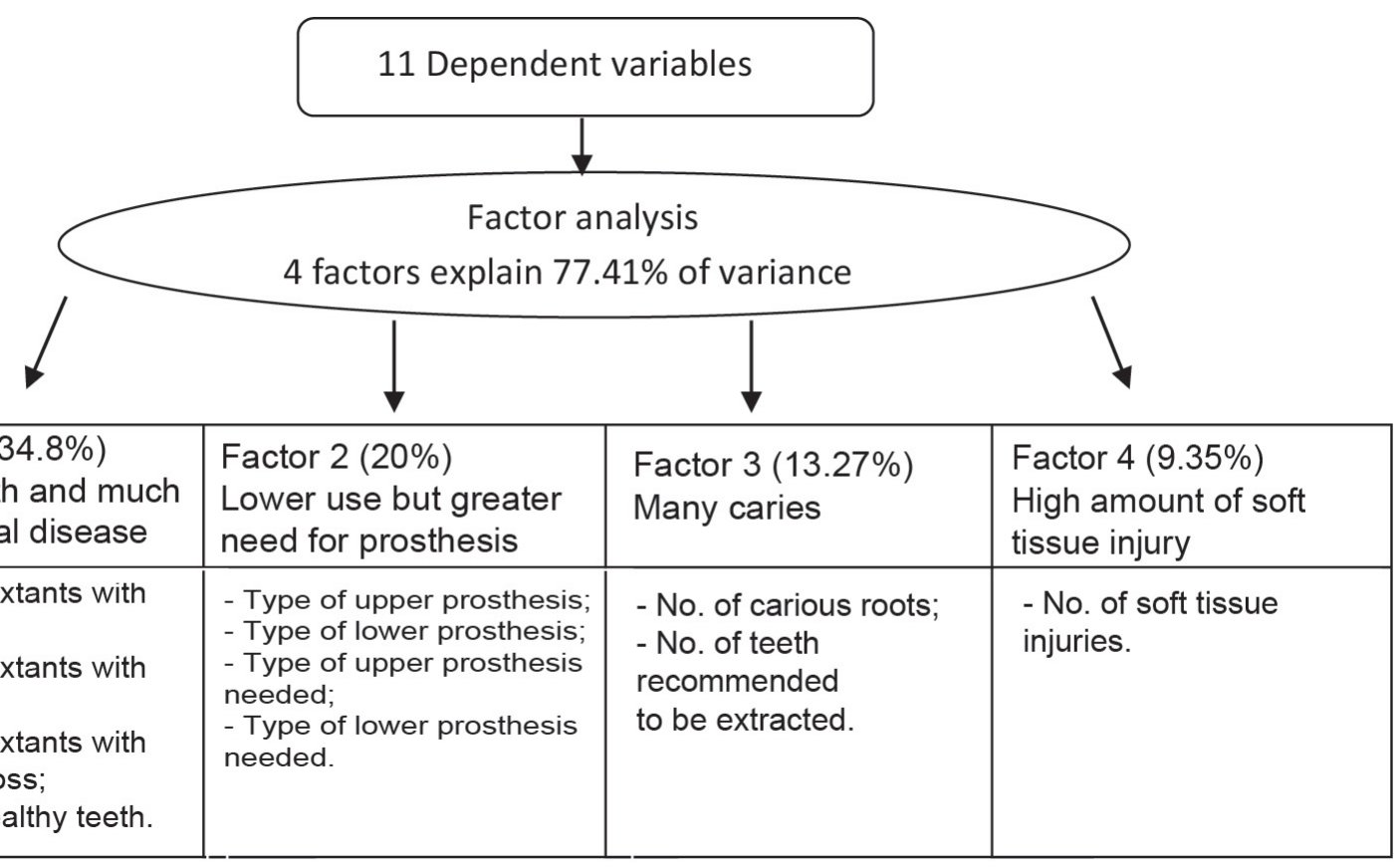

Figure 1. Results of the factor analysis process in the study of oral health conditions and functional capacity in a population of elderly persons. Natal, Rio Grande do Norte, 2011.

Bivariate analysis exhibited a significant association between the functional capacity of the elderly persons and the factorial variables of oral health related to the presence of caries (factor 3) and to the use or need for a prosthesis (factor 2). There was a lower incidence of dental caries among the majority of individuals who were dependent in at least one activity of daily living, while these individuals also presented a greater need for and less use of dental prostheses. The lower presence of dental caries in dependent individuals is most likely a result of their higher levels of tooth loss.
These associations, however, lost their statistical significance when adjustment was made for some confounding variables, combined in different models for each indicator. Some of the independent variables, on the other hand, did maintain their association with the factorial variables, for example: gender, age, presence of caregiver, main area of residence, time since last visit to dentist, type of service sought at said visit and self-perception regarding prosthesis replacement. The results of the association tests are presented in Table 2.

\begin{tabular}{|c|c|c|c|}
\hline $\begin{array}{l}\text { Factor } 1(34.8 \%) \\
\text { Many teeth and much } \\
\text { periodontal disease }\end{array}$ & $\begin{array}{l}\text { Factor } 2(20 \%) \\
\text { Lower use but greater } \\
\text { need for prosthesis }\end{array}$ & $\begin{array}{l}\text { Factor } 3(13.27 \%) \\
\text { Many caries }\end{array}$ & $\begin{array}{l}\text { Factor } 4(9.35 \%) \\
\text { High amount of soft } \\
\text { tissue injury }\end{array}$ \\
\hline $\begin{array}{l}\text { - No. of sextants with } \\
\text { bleeding; } \\
\text { - No. of sextants with } \\
\text { tartar; } \\
\text { - No. of sextants with } \\
\text { insertion loss; } \\
\text { - No. of healthy teeth. }\end{array}$ & $\begin{array}{l}\text { - Type of upper prosthesis; } \\
\text { - Type of lower prosthesis; } \\
\text { - Type of upper prosthesis } \\
\text { needed; } \\
\text { - Type of lower prosthesis } \\
\text { needed. }\end{array}$ & $\begin{array}{l}\text { - No. of carious roots; } \\
\text { - No. of teeth } \\
\text { recommended } \\
\text { to be extracted. }\end{array}$ & $\begin{array}{l}\text { - No. of soft tissue } \\
\text { injuries. }\end{array}$ \\
\hline
\end{tabular}




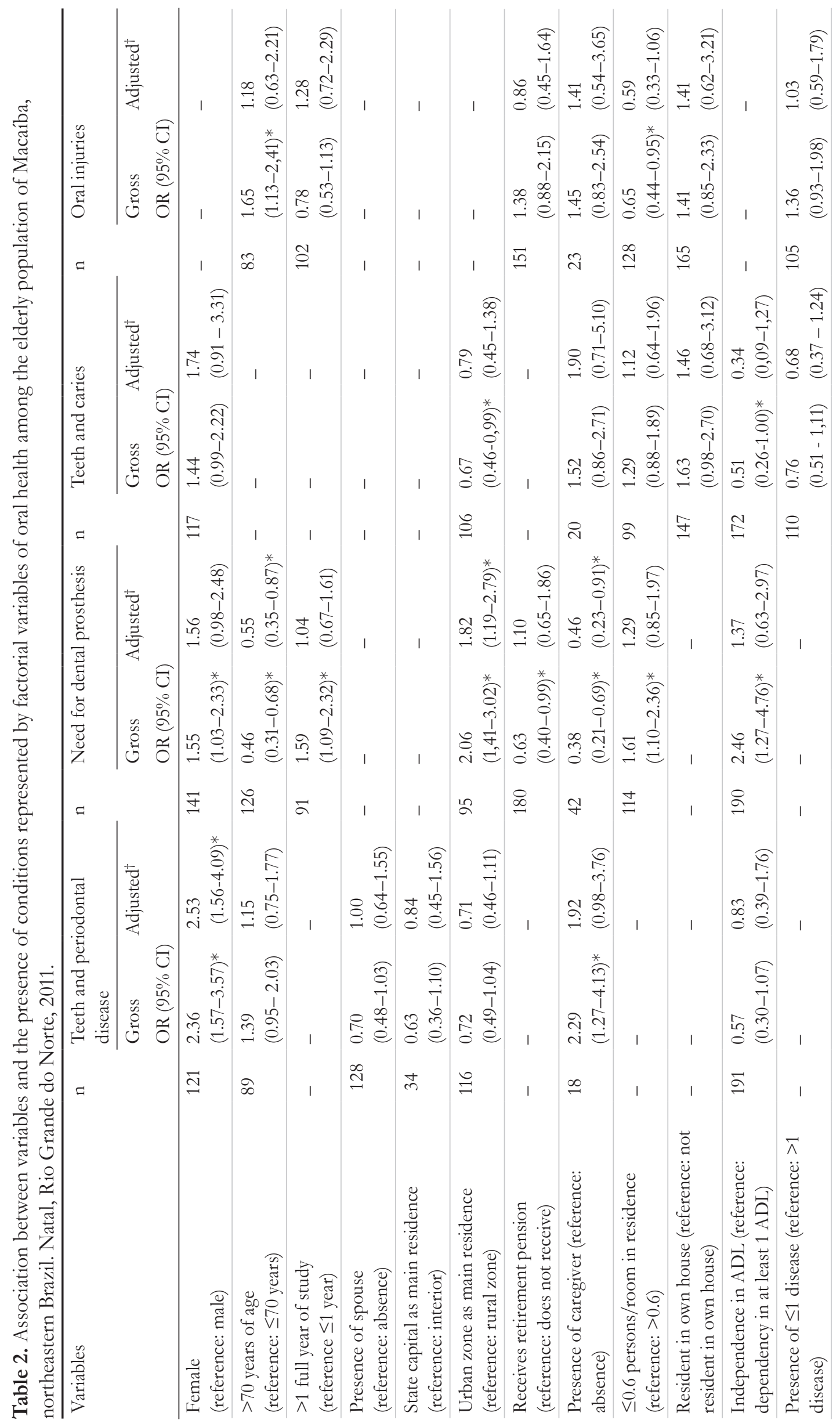




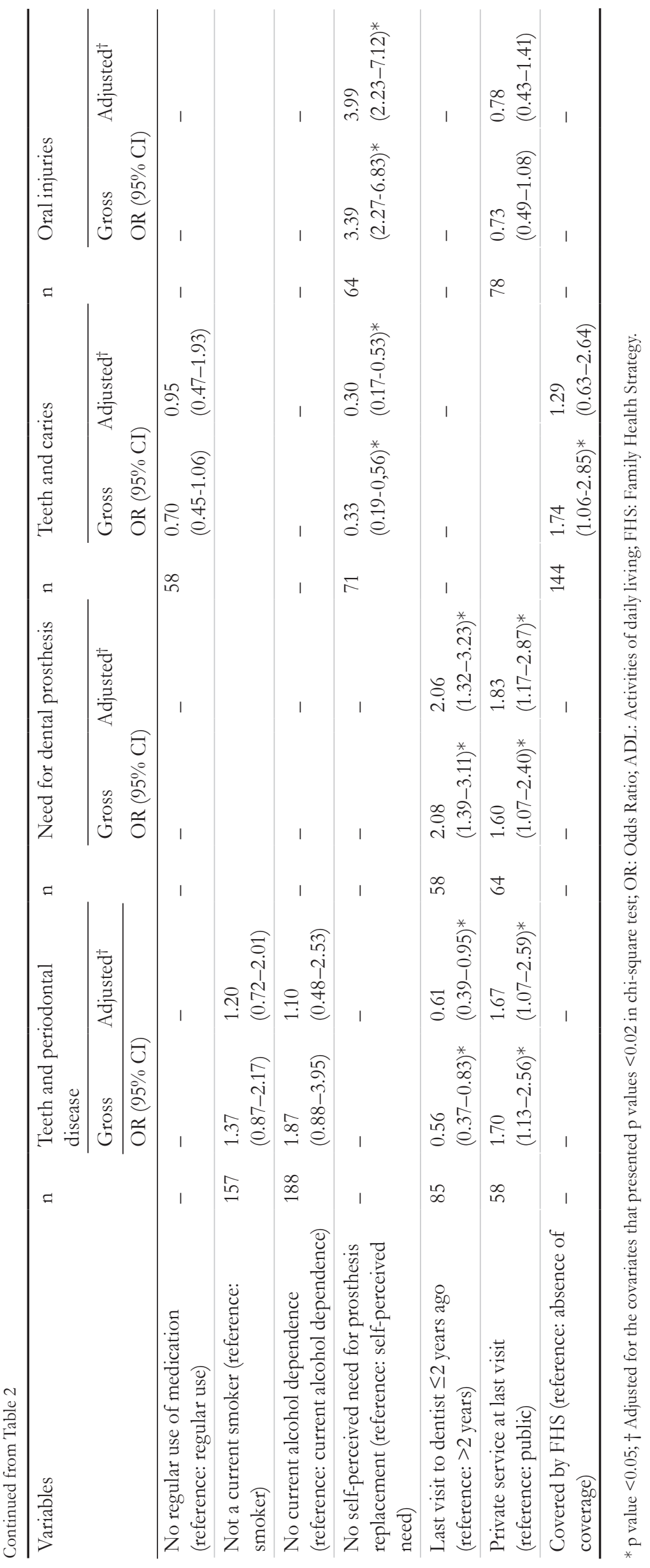




\section{DISCUSSION}

The results of the present study revealed there was no association between dental health status and functional capacity (increasingly important for the prognosis of the health status of the geriatric population ${ }^{17}$ ). This finding may be due to the fact that the condition of dependency among elderly individuals occurs at a different time of life from that at which oral problems are observed, with such issues representing the cumulative effects of a previous history of care deficiencies and invasive dentistry in these individuals.

The results of the present study are representative in terms of population due to the sampling procedures used as well the procedures and parameters employed in the calculation of the sample size. In addition, the results were corroborated when the sample was treated as complex, with compatible estimated mean and percentage values obtained. This treatment was performed due to the fact that a complex sample design, cluster sampling, was used in the study. It involved the assignment of individual weight values, representing the probability of each individual forming part of the study sample, considering their relevance to certain clusters (residence and census sector). Acceptable design effect values were also observed for the number of clusters considered in the sampling method, thus confirming the representativeness of the data for the population in question.

The first indicator of oral health, interpreted as "many teeth and much periodontal disease", was associated with gender, with a higher prevalence of males in this category. This association suggests elderly men neglect their oral health more than elderly women, who are generally more careful with their overall health. One study that analyzed the association between sociodemographic factors and the use of dental services among elderly Brazilians identified such negligence by men, finding an association between being male and never having visited a dentist ${ }^{18}$.

Time since last visit to the dentist was also associated with the first indicator, with a higher incidence of individuals whose last visit was more than two years ago in the many teeth and much periodontal disease category. This association demonstrates the importance of regular visits to the dentist for elderly persons, with a view not only to keeping their teeth, but also to maintaining healthy conditions. In this perspective, data from the national oral health survey conducted in 2002-2003 and presented in 2008 revealed a greater procuring of dental care among individuals with teeth remaining than among those who had no teeth ${ }^{19}$.

Finally, type of care sought on last visit to dentist was also associated with the first indicator, with a higher prevalence of periodontal disease among elderly persons who used a public service than those who sought out private care. This association is linked to the cumulative effects of the historical unreliability of the public model of dental care, based on iatrogenicinvasive, biologic, technical-centered and generally ineffective practices used with the general population and predominant in Brazil until the 1980 $\mathrm{s}^{20}$.

The second indicator of oral health provided by the factor analysis referred to the lower use and greater need for dental prosthesis. This indicator was associated with age, with more use and less need for a prosthesis among those elderly individuals aged up to 70 years. This suggests that there is a greater concern on the part of younger elderly persons regarding prosthetic rehabilitation, with a view to maintaining the functions that are lost when teeth are lost. On the other hand, older individuals tend to focus their concerns on other, more comprehensive and disabling health problems that give rise to greater debilities.

In this sense, Roncalli in $2006^{21}$ emphasized that among elderly individuals the presence of teeth may constitute an additional self-care difficulty, especially for those with functional limitations, and that the replacement of teeth with artificial teeth is not a cause for major concerns. Considering the practice of invasive dental treatment to which the elderly have been submitted, many of these individuals view tooth loss and edentulism as a normal and unavoidable stage of the evolution of their oral condition ${ }^{21,22,23}$.

There was also an association between the main area of residence category and the lower use and greater need for a dental prosthesis variable, with individuals who resided predominantly in rural areas showing a greater need for and lower use of prostheses. The cause of this association is most likely related to access to dental services, particularly the specialized services for dental prosthesis production that, despite being made available in Brazil through the Unified Health System as part of the National Oral Health Policy of 2006, are concentrated in urban centers, often making access difficult for rural residents ${ }^{24}$. 
Presence of a caregiver was also associated with the second indicator of oral health, with greater use and a lower need for a prosthesis presented by individuals who did not have such care support. The presence of a caregiver is generally associated with more dependent individuals, enabling this variable to serve as a proxy for functional capacity. With this in mind, the use of a prosthetic device could represent another aspect of the care needs of an individual as the prosthesis may require daily maintenance and hygiene skills on behalf of the user. Saliba et al in $2007^{25}$ and Simões and Carvalho in $2011^{26}$ indicated that the oral condition of elderly persons influences the type of care they are provided with and considered it important that caregivers are motivated to give proper attention to oral health.

Regarding the type of care sought on last visit to the dentist, individuals from the category of lower use and greater need for dental prosthesis were those most likely to have opted for a public service. This tendency is another that can be attributed to the unreliable dental care model, which in the public sector was characterized by public policies that excluded adult and elderly patients and ignored rehabilitative treatment ${ }^{21}$. The indicator of use of and need for prosthesis was also associated with time since last visit to the dentist, indicating that the majority of individuals whose last visit occurred more than two years ago used prostheses less and needed them more. This association demonstrates a relationship between self-care and oral health, with individuals who seek dental services more likely to have better oral health ${ }^{18}$, represented in this case by the timely replacement of lost teeth.

The oral health indicator related to the presence of caries was associated with self-perception regarding the need for the replacement of dental prosthesis, with a lower prevalence of caries among the majority of individuals who considered it necessary to replace their prosthesis. The probable cause of this is the precariousness of the oral health situation of the elderly persons, with individuals who thought prosthetic replacement unnecessary having more remaining teeth, and therefore more likely to be affected by an oral ailment such as caries or periodontal disease.

The above-mentioned variable (self-perception of the necessity of dental prosthesis replacement) was also associated with the presence of the soft tissue alterations indicator, with the majority of individuals who perceived a need to replace their prosthesis forming part of the group with a higher prevalence of injuries. The cause of this association may be that, in many cases, individuals perceived a need to replace their prosthesis because of an injury, such as prosthetic stomatitis and fibrous hyperplasia, which had been caused by a poorly fitted prosthesis ${ }^{27}$.

The absence of a direct effect caused by functional capacity on oral health conditions may be related to the limitations of the study with regards to the measurement of the dimensions investigated. It is likely that the condition of dependence experienced by elderly persons occurs at a different time of life from that when the consequences of oral problems are observed, with said problems in these individuals representing the cumulative effects of a history of deficient and invasive care. As with oral problems, dependency, characterized as a functional limitation, can be the result of a cumulative process, with chronic diseases that induce functional limitation, or else the presence of any chronic condition that does not receive proper care in order to maintain an acceptable physical balance. On the other hand, dependence may also result from an acute disabling condition, with individuals facing a sudden and progressive functional deficit ${ }^{4,8}$.

Therefore, in seeking associations between oral health status and functional capacity among elderly individuals, the present study found that identification of the point when an elderly person passes into a condition of dependence in some activities of daily living represents an important aspect to be considered in the possible identification of the effect of dependency on the oral health of said persons.

\section{CONCLUSION}

When associated with the oral health status of elderly persons, functional capacity did not display a direct effect. Associations with some other characteristics were, however, observed to be relevant among the individuals investigated, for example: age over 70 years, female gender, time since last visit to the dentist and type of service sought. These should be taken into consideration in clinical practice, with a view to achieving greater effectiveness in solving oral problems among elderly persons. It should be emphasized that in the search for associations between the dimensions investigated, identification of the point when each elderly person became dependent is a fundamental step and one that can, therefore, be considered as a limitation of the present study. 


\section{REFERENCES}

1. Kagawa CA, Corrente JE. Análise da capacidade funcional em idosos do município de Avaré-SP: fatores associados. Rev Bras Geriatr Gerontol. 2015;18(3):577-86.

2. Lebrão ML, Laurenti R. Saúde, bem-estar e envelhecimento: o estudo SABE no Município de São Paulo. Rev Brasi Epidemiol. 2005;8(2):127-41.

3. Pérez RCC, Yáñez SAB, Robledo LMG, Funes JAA. Oral health conditions and frailty in mexican community-dwelling elderly: a cross sectional analysis. BMC Public Health. 2012;12:1-12.

4. Moriya S, Tei K, Yamazaki Y, Hata H, Kitagawa Y, Inoue N, et al. Relationships between higher-level functional capacity and dental health behaviors in community-dwelling older adults. Gerodontology. 2013;30(2):133-40.

5. Saarela RKT, Soini H, Muurinen S, Suominen MH, Pitkälä KH. Oral hygiene and associated factors among frail older assisted living residents. Spec Care Dentist. 2012;33(2):56-61.

6. Naito M, Kato T, Fujii W, Ozeki M, Yokoyama M, Hamajima N, et al. Effects of dental treatment on the quality of life and activities of daily living in institutionalized elderly in Japan. Arch Gerontol Geriatr. 2010;50(1):65-8.

7. Petelin M, Cotic J, Perkic K, Pavlic A. Oral health of the elderly living in residential homes in Slovenia. Gerodontology. 2012;29(2):447-57.

8. Andrade FB, Lebrão ML, Santos JLF, Duarte YADO. Relationship between oral health and frailty in community-dwelling elderly individuals in Brazil. J Am Geriatr Soc. 2013;61(5):809-14.

9. Mello ALSF, Padilha DMP. Condições de higiene bucal de idosos residentes em instituições geriátricas de pequeno porte em Porto Alegre. Rev Fac Odontol. 2001;43(2):12-9.

10. Instituto Brasileiro de Geografia e Estatística. Resultados do Censo Demográfico [Internet]. Rio de Janeiro: IBGE; 2010 [acesso em 15 maio 2012]. Disponível em: http://www.ibge.gov.br/cidadesat/ link.php?uf $=$ rn

11. Brasil. Ministério da Saúde, Secretaria de Atenção à Saúde, Departamento de Atenção Básica. Projeto SB Brasil 2003: condições de saúde bucal da população brasileira 2002-2003: resultados principais. Brasília, DF: Ministério da Saúde; 2004.
12. Brasil. Ministério da Saúde, Secretaria de Atenção à Saúde, Departamento de Atenção Básica. Projeto SB Brasil 2010: Pesquisa Nacional de Saúde Bucal: manual da Equipe de Campo. Brasília, DF: Ministério da Saúde; 2010.

13. Roncalli AG. Aspectos técnico-operacionais de um levantamento epidemiológico em saúde bucal. In: Ferreira A, Roncalli AG, Lima KC, organizadores. Saúde bucal coletiva: conhecer para atuar. Natal: EDUFRN; 2006. p. 63-80.

14. Katz S, Ford AB, Moskovitz RW, Jackson BA, Jaffe MW. Studies of illness in the aged. The index of ADL: a standardized measure of biological and psychosocial function. J Am Med Assoc. 1963;185(12):914-9.

15. Fávero LP, Belfiore P, Silva FL, Chan BL. Análise Fatorial. In: Fávero LP, Belfiore P, Silva FL, Chan BL. Análise de dados: modelagem multivariada para tomada de decisões. Rio de Janeiro: ELSEVIER; 2009. p. 235-69.

16. Szwarcwald CL, Damacena GN. Amostras complexas em inquéritos populacionais: planejamento e implicações na análise estatística dos dados. Rev Bras Epidemiol. 2008;11(1):38-45.

17. Freitas RS, Fernandes MH, Coqueiro RS, Reis Júnior WM, Rocha SV, Brito TA. Capacidade funcional e fatores associados em idosos: estudo populacional. Acta Paul Enferm. 2012;25(6):933-9.

18. Matos DL, Giatti L, Lima MFC. Fatores sóciodemográficos associados ao uso de serviços odontológicos entre idosos brasileiros: um estudo baseado na Pesquisa Nacional por Amostra de Domicílios. Cad. Saúde Pública. 2004;20(5):1290-7.

19. Martins AMEBL, Haikal DS, Pereira SM, Barreto SM. Uso de serviços odontológicos por rotina entre idosos brasileiros: Projeto SB Brasil. Cad Saúde Pública. 2008;24(7):1651-66.

20. Roncalli AG. A organização da demanda em serviços públicos de saúde bucal [tese]. Araçatuba: Universidade Estadual Paulista, Faculdade de Odontologia; 2000.

21. Roncalli AG. Edentulismo. In: Antunes JLF, Perez MA. Epidemiologia da Saúde Bucal. Rio de Janeiro: Guanabara Koogan; 2006. p. 205-18.

22. Glassman P, Subar P. Creating and maintaining oral health for dependent people in institutional settings. J Public Health Dent. 2010;70(1):40-8. 
23. Hiramatsu DA, Tomita NE, Franco LJ. Perda dentária e a imagem do cirurgião-dentista em um grupo de idosos. Ciênc Saúde Coletiva. 2007;12(4):1051-6.

24. Brasil. Ministério da Saúde, Secretaria de Atenção à Saúde, Departamento de Atenção Básica, Coordenação Nacional de Saúde Bucal. Diretrizes da Política Nacional de Saúde Bucal: Brasília, DF: Ministério da Saúde; 2004.

Received: March 5, 2015

Reviewed: September 6, 2016

Accepted: November 7, 2016
25. Saliba NA, Moimaz SAS, Marques JAM, Prado RL. Perfil de cuidadores de idosos e percepção sobre saúde bucal. Interface Comun Saúde Educ. 2007;11(21):39-50.

26. Simões ACA, Carvalho DM. The reality of the oral/ dental health of the elderly in the Brazilian Southeast. Ciênc Saúde Coletiva. 2011;16(6)2975-82.

27. Martins AMEBL, Barreto SM, Pordeus AI. Fatores relacionados à autopercepção da necessidade de tratamento odontológico entre idosos. Rev Saúde Pública. 2008;42(3):487-96. 